\title{
Too young to be a wife! analysis of the factors influencing child marriages and its influence on the preferred number of children among women in Zambia.
}

\author{
James Mulenga ${ }^{1}$, Mulenga Chonzi Mulenga ${ }^{1}$, Bwalya Bupe Bwalya ${ }^{2}$ \\ \& Christabel Ngongola-Reinke ${ }^{1}$ \\ ${ }^{1}$ Department of Economics, School of Social Science, Mulungushi University, \\ Kabwe, Zambia. \\ ${ }^{2}$ Department of Mathematics and Statistics, School of Sciences, Engineering and Technology, \\ Mulungushi University, \\ Kabwe, Zambia \\ Email:nileshmulenga@gmail.com
}

\begin{abstract}
Context/Background: Zambia has one of the highest rates of child marriages in the world. This study sought to establish the determinants of child marriage in rural and urban areas of Zambia, and to determine the influence of child marriage on fertility preferences of women in Zambia.

Data source and methods: The study utilized data from the 2013-2014 Zambia Demographic Health Survey. Data was analysed using the Binary Logistic and Poisson regression models.

Results: Timing of conception, age at first sex, region of residence, education level of respondent and their partners, and family size were significant predictors of child marriages in urban areas. In rural areas, region of residence, age at fist sex, education level of respondent and their partners, and family size had significant influence on child marriages. The study further found that women who got married below the age of 18 preferred a higher number of children.

Conclusion: The study established that various factors influence child marriages in urban and rural Zambia and in turn child marriages influence the preferred number of children. The findings suggest a multipronged approach to addressing the root cause of the problem.
\end{abstract}

Keywords: Child marriage, Logistic, Poisson, Incident Rate Ratio, fertility.

\section{Introduction}

Child marriage is a global phenomenon which has disproportionate consequences on the girl child, their children and society at large. Child marriages are usually triggered by poverty, lack of education, culture, and lack of employment among others (Nour, 2006). Various studies have highlighted that child marriages have negative consequences relating to educational prospects, child health \& nutrition, maternal morbidity \& mortality, fertility, and partner violence (Wodon, et al. 2017; Efevbera, 2017; CSO et al. 2014; Godha, 2013; Smith, et al. 2012). Globally, there is increasing awareness of these negative consequences of child marriages as reflected in the Sustainable Development Goal (SDG) target number 5.3 which sets to "eliminate all harmful practices, such as child, early and forced marriage and female genital mutilations" by 2030 (United Nations, 2016).

Although there are global variations in the definition of child marriage, however, the universally accepted definition is that which occurs before the age of 18 (UNICEF, 20I4). According to the Convention on the Rights of the Child, a child refers to a human being below the age of eighteen years unless under the law applicable to the child, maturity is attained earlier. United Nations Population Fund (UNFPA) and the African Charter on the Rights and Welfare of the Child (Year) define child marriage as marriage before the age of 18. Moreover, the definition of child marriage as any marriage occurring before the 18th birthday has been used in various studies including (Wodon, et al. 2017; Godha, et al 2013; Nour, 2006).

Globally, there has been tremendous reduction in child marriage over the years. UNICEF (2018) estimates that $21 \%$ of the young women (aged 20 to 24) were married before the age of 18 years and currently the total number is approximately 650 million. Despite the fact that child marriage is practiced world over, it is more rampant in developing countries particularly in the Sub-Sahara African (SSA) countries (UNICEF, 20I4). SubSaharan African Countries account for the highest proportions (38\%) of child marriages followed by South Asia with $30 \%$. The lowest proportions are found in Eastern Europe and Central Asia (1 I\%). 
In Zambia, child marriage has only reduced marginally from $54 \%$ in 1992 to $42 \%$ in 2014 (as highlighted in figure I) and this makes Zambia one of the countries with the highest rates of child marriages in the world. Age at first marriage however, is unequally distributed across the provinces in Zambia.
Generally, the median age is lower in provinces with high incidence of poverty as presented in figure $\mathrm{I}$. The backdrop has led to renewed debate on the issue of child marriages in Zambia with Government proposing to increase the age of marriage to 21 years.

Figure 1. Trend in child marriage for ladies aged from 20 to 49: ZDHS 1992 to 2014
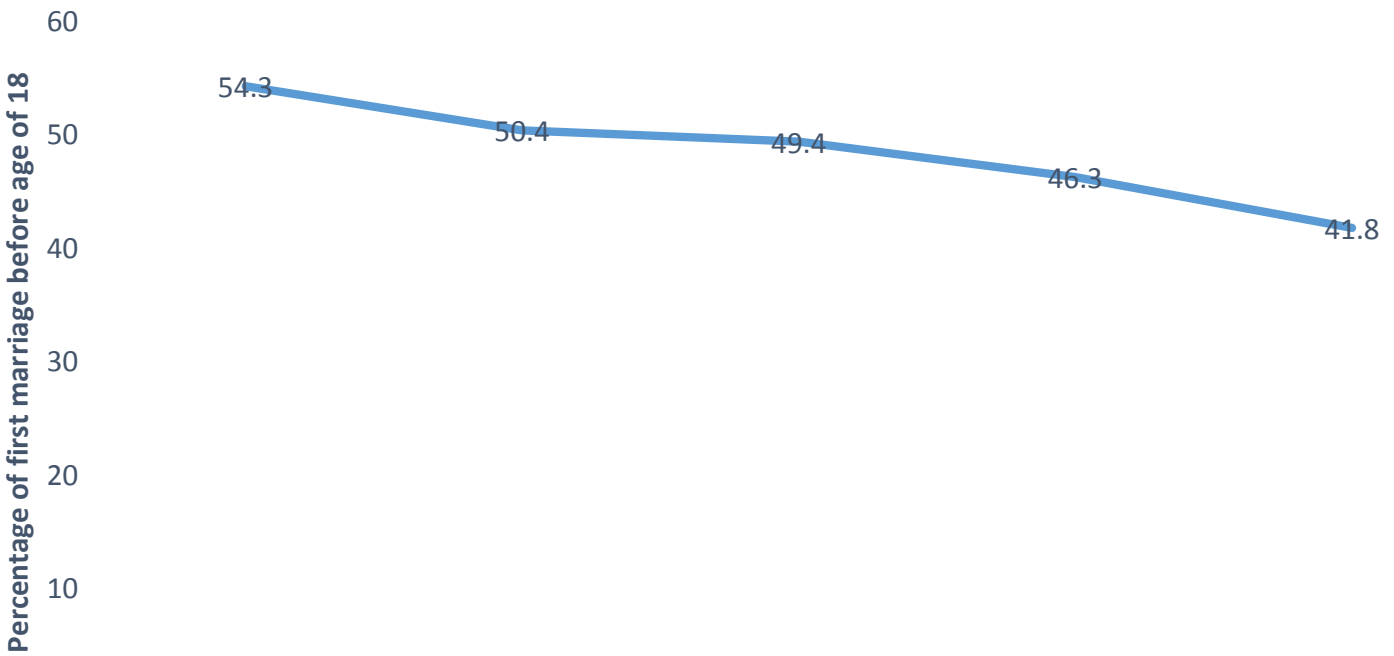

0

1992

1996

$2001 / 2002$

2008

$2013 / 14$

Figure 2: Headcount poverty and median age at first marriage among women age 20-49 by province, Zambia, 2015.

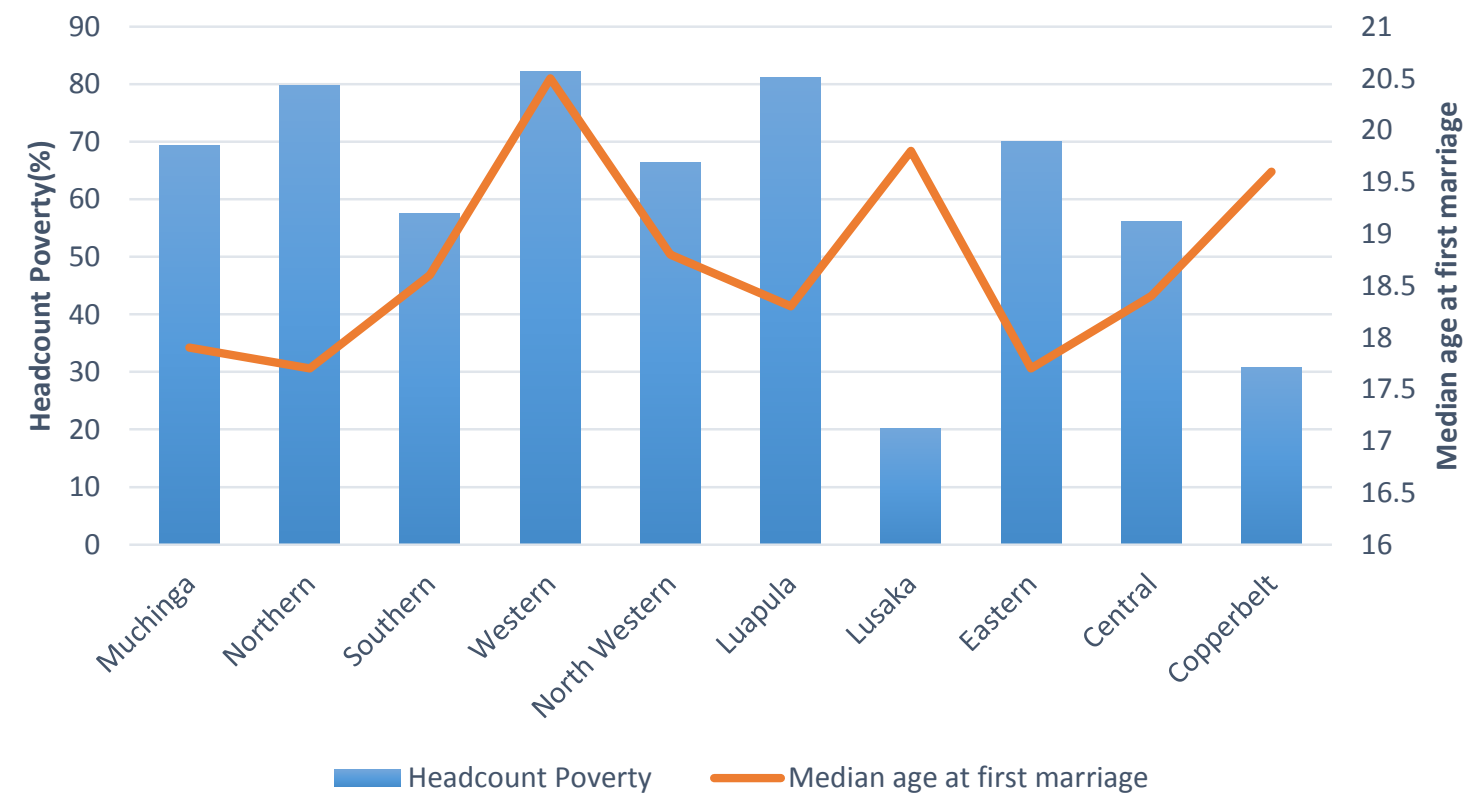

In a bid to reduce the child marriage rates, the Government of the Republic of Zambia(GRZ) has put in place various strategies such as the National Strategy on Ending Child Marriage in Zambia 2016 2021 . The Strategy aims to achieve a $40 \%$ reduction in child marriage by 202I (GRZ, 20I6). Achieving this milestone requires a multipronged approach targeting not only the socioeconomic factors influencing women but also the legal and cultural issues. From the legal point of view, Zambia follows a dual legal system which presents conflicting definitions of marriage. While on the one hand the Marriage Act stipulates that for a marriage to take place, one has to be at least 21 years, and could obtain parental consent if between the ages of 18 and 21 , but on the 
other hand the customary law makes no prescription on the required age (Nsemukila 20I5; Panos 20I4).

In view of the foregoing this study wishes to investigate some of the reasons behind the high prevalence of child marriage in Zambia. By so doing, this study provides some input to the current debate and gives a full understanding of the effects and consequences of child marriage. Thus, the study takes a balanced approach by establishing the factors that influence child marriages and also determining the effect of child marriages on fertility.

\section{Literature review}

A number of studies have been undertaken in various countries to establish the root causes of child marriages as well as its various social, economic and health effects. In their quest to find the determinants and impact of early marriage on the mother and her newborn in an urban area of Davangere in India, Sandhu et al. (2017) observed that literacy and socioeconomic status of the mother were major determinants in deciding the age at marriage. Similarly, Ali et al (20I4) observed that child marriage was more common among women with less than secondary education, whose parents and husbands had less than secondary education. A study by Green et al (2009) in Uganda found that poverty and limited education were associated with child marriages. The study further noted that cultural traditions and social norms such as bride price, preventing premarital pregnancy, preserving girls' virginity until marriage, and providing them with the financial security, drivers of early marriages in Uganda. A related study by Birech (20/3) observed that culture continues to perpetuate and entrench the practice of child marriage in Kenya.

Another child marriage influencing variable is place of residence (Ali, 20l4; Walker et al. 20I3). It is argued that rural based girls and women tend to marry earlier than their urban counterparts. Further, perceived ideal marital age, knowledge of legal marital age and knowing someone who was accused of an early marriage crime have been noted to be determinants of early marriage practice (UNFPA 20I3; Walker et al. 20I3). A study by Maswikwa, et al. (2015) found that inconsistent laws against child marriage are negatively associated with the prevalence of child marriage and adolescent birth.

In Zambia, only a few studies have been undertaken to establish the causes of child marriage. Using the DHS datasets for three SSA countries namely Ghana, Kenya and Zambia to study the trends and determinants of female age at first marriage, Amoo(2017) found that women with tertiary education and from rich households had lower hazard ratio to marry under the age of I8.Further, a qualitative study of six districts in Zambia by Mann et al. (20I5) observed that child marriage was likely to take place among children from poor families or backgrounds, living in rural areas, not attending school, pregnant girls, orphans and stepchildren, difficult or 'hard to manage' children, and children without adequate supervision or support.

Child marriage is a worldwide problem with a variety of health and social consequences. It can cause untold suffering to the victims; limit the child's education and place the girl child in a disadvantaged position (Birech, 20/3). In fact it can perpetuate inequalities and poverty situations among the affected. CSO, et al. (2003) contends that early marriages tend to lead to early childbearing, a higher number of births and higher fertility. Various studies (Wodon, et al. 2017; Godha, 2013; Adhikari, 2010; Nour, 2006) show that child marriage has a large impact on fertility as those who marry earlier have higher probabilities of having more children. A multicounty study by Godhac (20/3) on the association between child marriage and reproductive health outcomes and service utilization in South Asia suggests that child marriage is significantly associated with a history of rapid repeat childbirths. Similarly, Adhikari (2010) while studying the demographic, socio-economic, and cultural factors affecting fertility differentials in Nepal using DHS data found that women who married late, exposed to mass media, and were literate had lower number of children ever born.

\section{Data and methods}

\section{Population, sample size and data}

This study utilized data from the 2013-14 Zambia Demographic and Health Survey. The survey was nationally representative and employed a two-stage stratified sampling design. It used a semi-structured questionnaire to collect data from 16,258 occupied households. From these households, a total of 17,064 women age 15-49 were identified as eligible for individual interviews, and $|6,4| \mathrm{I}$ of these women were successfully interviewed indicating a $96.2 \%$ response rate.

\section{Variables: outcome}

There are two outcome variables in this study, namely; 'child marriage' and 'preferred number of children'. Therefore, two models were used. The first model used age at first marriage/cohabitation to determine child marriage. The response for age at first marriage/cohabitation was coded I for age below 18 years and 0 for those aged 18 years and above. The second model used the preferred number of children. 


\section{Variables: independent}

Based on the existing empirical literature and availability in the 20/3-I4 ZDHS, the following variables were considered as independent variables for the analysis: educational level (grouped into; no education, primary education, secondary education or higher), respondents employment status (unemployed or employed); Media Access (a sum of; frequency of reading newspaper, listening to radio and watching television) and recoded into (No access or Access to media), respondents household wealth index (recoded as poor, middle or rich); family size(recoded into less than 6, 6 to 10, more than 10); age at first sex(recoded into sex before age of 16 , sex at age 16 and above); place of residence (urban or rural), and interval between marriage and birth (recoded as post-marital Conception, pre-marital conception and pre-marital births).

\section{Data analysis}

Data was analysed using STATA I 4.0 software and it involved two types of analyses; descriptive and inferential. Descriptive analysis was undertaken to examine the percentage distribution of the variables of interest. Inferential analysis involved the use of the Binary Logistic and the Poisson regression models.

A. Factors influencing child marriages: The Logistic regression model and its associated marginal (discrete) effects was applied to establish the factors that influence child marriages as well as to compare how well each of these models explained the situation at hand. As a requirement for undertaking the Binary Logistic regression analysis, the age at first marriage was recoded into a dichotomous variable.
B. Association between child marriages and fertility: The Count data regression model was used to analyse the association between child marriages and fertility. Count data models, specifically the Poisson Regression Model are used when the outcome variable is concentrated on a few small discrete values. The analysis considered the incidence rate ratio (IRR).

Before undertaking the regression analyses, the variables were tested for the presence of multicollinearity using the method of pairwise correlation. The regression analyses were performed at $5 \%$ level of significance and all the variables were weighted to account for the probabilities of unequal sample selection used by the 2013-I4 ZDHS.

\section{Results}

\section{Description of the study sample}

Table I below presents the key characteristics of the sample. The table shows that, about half of the married women interviewed got married below the age of 18 years and about $41.3 \%$ of the women resided in urban areas. In addition, $38.3 \%$ belonged to households classified as poor while $42 \%$ were from rich households. The table also shows that $42.7 \%$ of the women had their first sex before the age of 18 years. In terms of education, over half $(50.7 \%)$ of the women had primary education, while $36 \%$ had secondary education. Moreover, a greater proportion of the women's partners had secondary education $48.3 \%$. The table also shows that the majority of the women had access to some form of media (76.5\%).

Table I: Percentage distribution of the characteristics of the sample.

\begin{tabular}{lll}
\hline Variable & Percent & Count \\
\hline Age at first marriage & & \\
I8+ Years & 57.3 & 3,046 \\
$<$ I8 Years & 42.7 & $2,27 \mid$ \\
Age at First Sex & & \\
I6+ Years & 66.9 & 3,555 \\
$<$ I6 years & 33.1 & 1,762 \\
Timing of Conception & & \\
Post-marital Conception & 49.8 & 2,649 \\
Pre-marital Conception & 18.3 & 975 \\
Premarital Births & 31.8 & 1,692 \\
Family Size & & \\
I-5 Members & 45.4 & 2,416 \\
6-I0 Members & 47.5 & 2,526 \\
$>$ I0 Members & 7.1 & 375 \\
Type of place of residence & & \\
Urban & 45.5 & 2,419 \\
Rural & 54.5 & 2,898 \\
http://aps.journals.ac.za & &
\end{tabular}




\section{Wealth Quintile}

Poor

Middle

Rich

Educational level

None

Primary

Secondary

Tertiary

Employment status

Unemployed

Employed

Educational Level of Partner

None

Primary

Secondary

Tertiary

Media exposure

No exposure

Exposed to media

$\begin{array}{ll}33.4 & 1,776 \\ 19.6 & 1,041 \\ 47 & 2,501\end{array}$

7.5

397

$50.7 \quad 2,698$

$36 \quad 1,916$

$5.8 \quad 306$

$41.5 \quad 2,206$

$58.5 \quad 3,110$

4. 1

217

36.5

1,941

$48.3 \quad 2,569$

II.I 590

23.5

I,252

76.5
Factors associated with child marriages in Zambia Table 2 presents the bivariate analysis results for child marriage status among women aged I5 - 49. Overall, child marriages varied significantly across region of residence, with Eastern province accounting for the highest proportion (61.7\%) and Western province the lowest (34.4\%). The results also show that over half of the child marriages were more likely to occur in the rural areas (55.3\%) and in households classified as poor $(56.9 \%)$. Women who had their first sexual debut before the age of 16 and those with no education were $60 \%$ more likely to be married before the age of 18 .

Table 2: Percentage distribution of child marriage status among women aged I5 - 49 by key variables

\begin{tabular}{|c|c|c|c|c|c|}
\hline & \multicolumn{2}{|c|}{ Overage marriage } & \multicolumn{2}{|c|}{ Child marriage } & \multirow{2}{*}{$\begin{array}{c}\mathrm{P}- \\
\text { value }\end{array}$} \\
\hline & $\%$ & $\mathrm{Cl}$ & $\%$ & $\mathrm{Cl}$ & \\
\hline \multicolumn{6}{|l|}{ Region } \\
\hline Central & 48.2 & {$[44.1,52.3]$} & 51.8 & {$[47.7,55.9]$} & \multirow{10}{*}{0.000} \\
\hline Copperbelt & 55 & {$[50.8,59.0]$} & 45 & {$[4 \mid .0,49.2]$} & \\
\hline Eastern & 38.3 & {$[35.3,41.4]$} & 61.7 & {$[58.6,64.7]$} & \\
\hline Luapula & 49.1 & {$[45.2,52.9]$} & 50.9 & {$[47.1,54.8]$} & \\
\hline Lusaka & 57.4 & {$[53.1,61.6]$} & 42.6 & {$[38.4,46.9]$} & \\
\hline Muchinga & 43.4 & {$[40.1,46.7]$} & 56.6 & {$[53.3,59.9]$} & \\
\hline Northern & 40.8 & {$[37.4,44.3]$} & 59.2 & {$[55.7,62.6]$} & \\
\hline North Western & 51.2 & {$[47.0,55.3]$} & 48.8 & {$[44.7,53.0]$} & \\
\hline Southern & 51.2 & {$[47.6,54.7]$} & 48.8 & {$[45.3,52.4]$} & \\
\hline Western & 65.6 & {$[61.6,69.5]$} & 34.4 & {$[30.5,38.4]$} & \\
\hline \multicolumn{6}{|c|}{ Type of place of residence } \\
\hline Urban & 58.3 & {$[55.7,60.8]$} & $4 I .7$ & {$[39.2,44.3]$} & \multirow{2}{*}{0.000} \\
\hline Rural & 44.7 & {$[43.2,46.2]$} & 55.3 & {$[53.8,56.8]$} & \\
\hline \multicolumn{6}{|l|}{ Wealth Index } \\
\hline Rich & 60 & {$[57.4,62.5]$} & 40 & {$[37.5,42.6]$} & \multirow{3}{*}{0.000} \\
\hline Middle & 44.9 & {$[42.4,47.4]$} & 55.1 & {$[52.6,57.6]$} & \\
\hline Poor & 43.1 & {$[41.4,44.8]$} & 56.9 & {$[55.2,58.6]$} & \\
\hline 4323 & & & & http:// & .journa \\
\hline
\end{tabular}




\begin{tabular}{llllll} 
Pre-Post Marital Conception & & & & & \\
Post-marital Conception & 37.9 & {$[36.2,39.5]$} & 62.1 & {$[60.5,63.8]$} & \\
Pre-marital Conception & 50.4 & {$[47.7,53.1]$} & 49.6 & {$[46.9,52.3]$} & 0.000 \\
$\begin{array}{l}\text { Pre-marital Births } \\
\text { Age at First Sex }\end{array}$ & 82.1 & {$[80.2,83.8]$} & 17.9 & {$[16.2,19.8]$} & \\
Legal Age Sex & 67 & {$[65.2,68.7]$} & 33 & {$[31.3,34.8]$} & 0.000 \\
Underage Sex & 38.2 & {$[36.1,40.4]$} & 61.8 & {$[59.6,63.9]$} & \\
Educational level & & & & & \\
None & 37.2 & {$[34.1,40.3]$} & 62.8 & {$[59.7,65.9]$} & \\
Primary & 41.4 & {$[39.9,42.8]$} & 58.6 & {$[57.2,60.1]$} & 0.000 \\
Secondary & 64.8 & {$[62.7,66.9]$} & 35.2 & {$[33.1,37.3]$} & \\
Tertiary & 94.3 & {$[91.4,96.3]$} & 5.7 & {$[3.7,8.6]$} & \\
\hline
\end{tabular}

Rural-urban differentials in child marriages among the women aged I5 - 49.

Table 3 shows adjusted odds ratios of the factors influencing child marriages among women aged between 15 - 49 in Zambia disaggregated by type of place of residence. The table shows that women residing in the urban parts of North-Western and Western Provinces had $31 \%$ and $48 \%$ lower odds of getting married below the age of 18 respectively, compared to those residing in Lusaka. On the other hand, women residing in the rural parts of Copperbelt, Eastern and Southern Provinces had $82 \%, 48 \%$ and $45 \%$ higher odds of getting married below the age of 18 respectively, while those from Western Province had 39\% lower odds of getting married below the age of 18, compared to those residing in Lusaka. In both the rural areas and urban areas, conceiving or giving birth before marriage did not trigger child marriages. Women who conceived before marriage had $34 \%$ and $36 \%$ lower odds of getting married below the age of 18 for urban and rural areas respectively. Similarly, women who gave birth before marriage were $88 \%$ and $87 \%$ less likely to get married before the age of 18. Age at first sex was found to be a major driver for child marriages. Women who had their first sex before the age of 16 had $323 \%$ higher odds and $220 \%$ higher odds of getting married before the age of 18 . In both urban and rural areas, women who had tertiary education and whose partners had tertiary level of education had lower odds of getting married before the age of 18. Family size was found to have a positive influence on child marriages, with an increase in family size by one person increasing the odds of getting married before the age 18 by $27 \%$ in urban areas and $12 \%$ in rural areas.

Figure 3: Logistic Regression Results of the Determinants of Child Marriage among Married Women aged 15 to 49 by type of place of residence

\begin{tabular}{|c|c|c|c|c|}
\hline \multirow[b]{2}{*}{ Variable } & \multicolumn{2}{|c|}{ Child marriage: Urban } & \multicolumn{2}{|c|}{ Child Marriage: Rural } \\
\hline & AOR & $\mathrm{Cl}$ & AOR & $\mathrm{Cl}$ \\
\hline \multicolumn{5}{|l|}{ Region } \\
\hline Lusaka & I & & I & \\
\hline Central & 0.93 & $0.72-1.20$ & 1.29 & $0.93-1.80$ \\
\hline Copperbelt & 0.93 & $0.7 \mid-1.20$ & $1.82 * * * *$ & I. $30-2.56$ \\
\hline Eastern & 0.96 & $0.73-1.25$ & I. $.48 * * * * *$ & $1.08-2.03$ \\
\hline Luapula & 0.86 & $0.62-1.18$ & 0.83 & $0.60-1.16$ \\
\hline Muchinga & 1.04 & $0.80-1.35$ & 0.95 & $0.69-|.3|$ \\
\hline Northern & 1.09 & $0.84-1.42$ & 1.02 & $0.73-|.4|$ \\
\hline North Western & $0.69 * * *$ & $0.51-0.93$ & 1.19 & $0.85-1.66$ \\
\hline Southern & 0.92 & $0.68-1.25$ & $1.45^{* * * *}$ & $1.06-1.99$ \\
\hline Western & $0.52 * * * *$ & $0.36-0.73$ & $0.6 I^{* * * *}$ & $0.42-0.87$ \\
\hline \multicolumn{5}{|l|}{ Wealth index } \\
\hline Rich & & & I & \\
\hline Middle & 1.11 & $0.88-1.42$ & 1.10 & $0.84-1.45$ \\
\hline Poor & 1.10 & $0.76-1.60$ & 0.97 & $0.75-1.26$ \\
\hline \multicolumn{5}{|l|}{ Conception/Ist Birth Timing } \\
\hline Post-marital conception & & & I & \\
\hline Premarital conception & $0.66^{* * *}$ & $0.51-0.85$ & $0.64^{* * *}$ & $0.55-0.75$ \\
\hline tp://aps.journals.ac.za & & & & 4324 \\
\hline
\end{tabular}




\begin{tabular}{|c|c|c|c|c|}
\hline \multicolumn{5}{|l|}{$\begin{array}{l}\text { Premarital Births } \\
\text { Age at First Sex }\end{array}$} \\
\hline Off age & & & I & \\
\hline Underage Sex & 4.23**** & $3.36-5.31$ & $3.20 * * *$ & $2.75-3.72$ \\
\hline \multicolumn{5}{|l|}{ Educational level } \\
\hline None & & & I & \\
\hline Primary & 1.21 & $0.86-1.68$ & 0.90 & $0.76-1.08$ \\
\hline Secondary & 0.71 & $0.48-1.04$ & $0.48^{* * * *}$ & $0.39-0.61$ \\
\hline Tertiary & $0.10 * * *$ & $0.05-0.20$ & 0.20 *** & $0.09-0.47$ \\
\hline \multicolumn{5}{|l|}{ Mass media } \\
\hline No Exposure & & & I & \\
\hline Exposed & 0.92 & $0.71-1.19$ & 0.97 & $0.85-1.12$ \\
\hline Family Size & I. 27 ***** & $1.07-1.50$ & I. $12^{* * * *}$ & $1.00-1.25$ \\
\hline \multicolumn{5}{|l|}{ Religion } \\
\hline Catholic & & & I & \\
\hline Protestant & 0.96 & $0.75-1.22$ & 0.91 & $0.78-1.07$ \\
\hline Muslim & 0.42 & $0.17-1.02$ & 0.75 & $0.27-2.10$ \\
\hline Other & 0.65 & $0.26-1.61$ & 0.77 & $0.47-1.24$ \\
\hline \multicolumn{5}{|c|}{ Educational Level of Partner } \\
\hline None & & & I & \\
\hline Primary & 0.91 & $0.52-1.60$ & 1.20 & $0.98-1.48$ \\
\hline Secondary & 0.77 & $0.45-1.32$ & 0.91 & $0.73-1.13$ \\
\hline Tertiary & $0.43^{* * * *}$ & $0.23-0.78$ & $0.33^{* * * *}$ & $0.19-0.56$ \\
\hline Constant & 1.27 & $0.67-2.42$ & 1.26 & $0.82-1.95$ \\
\hline
\end{tabular}

Influence of child marriages on fertility preference among women in Zambia.

Table 4 below shows the association between the preferred number of children and age at first marriage. The unadjusted incident rate for women who got married before the age of 18 was 1.12 times the incidence rate for those who got married at 18 years old and above. Table 5 below further shows the multiple Poisson regression results of the factors influencing the preferred number of children. The results are presented as Adjusted Incidence Rate Ratio (AIRR). The incident rate for women who got married before the age of 18 was 1.04 times the incidence rate for those who got married at 18 years old and above, holding the other variables constant. This implies that for women who got married below the age of 18 , their preferred number of children was 1.04 times as those who got married at 18 years old and above. Employment status was associated with higher fertility among never married women; employed women had about an incident rate of I.07. The results also show that respondents with primary, secondary and tertiary education had incident rates of $0.94,0.87$ and 0.75 respectively. Education level of partners had similar effects. Rural based women also preferred a higher $(A I R R=1.08)$ number of children compared with their urban counterparts.

Table 4: Unadjusted Incident Rate Ratio for the association between age at first marriage and preferred number of children

\begin{tabular}{lll}
\hline & \multicolumn{2}{l}{ Preferred Number of children } \\
\cline { 2 - 3 } VARIABLE NAME & IRR & CI \\
\hline Age at first marriage & & \\
I + Years & & \\
$<18$ Years & $1.12^{* * * *}$ & $1.09-1.15$ \\
Constant & $4.75^{* * *}$ & $4.67-4.83$ \\
\hline *** $<<05$ & &
\end{tabular}


Table 5: Adjusted Incident Rate Ratio for factors influencing the preferred number of children

\begin{tabular}{|c|c|c|}
\hline \multirow[b]{2}{*}{ VARIABLE NAME } & \multicolumn{2}{|c|}{ Preferred number of children } \\
\hline & AIRR & $\mathrm{Cl}$ \\
\hline \multicolumn{3}{|l|}{ Age at first marriage } \\
\hline $18+$ Years & I & \\
\hline$<18$ Years & I.03**** & $1.00-1.06$ \\
\hline \multicolumn{3}{|l|}{ Age at First Sex } \\
\hline $16+$ Years & I & \\
\hline$<16$ years & 1.01 & $0.98-1.03$ \\
\hline \multicolumn{3}{|l|}{ Family Size } \\
\hline I to 5 Members & I & \\
\hline 6 to 10 Members & I.15**** & $1.12-1.18$ \\
\hline$>10$ Members & I.2I **** $^{2}$ & $1.15-1.27$ \\
\hline \multicolumn{3}{|l|}{ Media exposure } \\
\hline No media exposure & I & \\
\hline Exposed to media & $0.96 * * *$ & $0.93-0.99$ \\
\hline \multicolumn{3}{|c|}{ Type of place of residence } \\
\hline Urban & I & \\
\hline Rural & $1.07 * * *$ & $1.03-1.10$ \\
\hline \multicolumn{3}{|l|}{ Wealth Quintile } \\
\hline Poor & I & \\
\hline Middle & 0.99 & $0.95-1.02$ \\
\hline Rich & $0.95 * * *$ & $0.91-0.99$ \\
\hline \multicolumn{3}{|l|}{ Educational level } \\
\hline None & I & \\
\hline Primary & $0.95^{* * * *}$ & $0.91-1.00$ \\
\hline Secondary & $0.87^{* * * *}$ & $0.82-0.91$ \\
\hline Tertiary & $0.79 * * *$ & $0.72-0.85$ \\
\hline \multicolumn{3}{|l|}{ Employment status } \\
\hline Not employed & I & \\
\hline Employed & I.07**** & $1.04-1.10$ \\
\hline \multicolumn{3}{|c|}{ Educational Level of Partner } \\
\hline None & I & \\
\hline Primary & 1.00 & $0.95-1.07$ \\
\hline Secondary & 0.95 & $0.90-1.01$ \\
\hline Tertiary & $0.90^{* * * *}$ & $0.83-0.97$ \\
\hline
\end{tabular}

\section{Discussion of findings}

Factors influencing child marriages

Initiation into marriage in Zambia occurs quite early with the results of this study showing that over $40 \%$ of women get married before the age of eighteen. This result confirms the results of studies undertaken in other developing countries which have found a high prevalence of child marriages (UNICEF, 20II; Raj, 2010; Nour, 2009). In addition, the study finds that the prevalence of child marriages in Zambia is high among women who reside in rural areas (59\%), have low wealth (middle and poor wealth quintiles combined) (58\%) and were educated only up to primary level $(55 \%)$. The plausible explanation could be that since Zambia is characterized by a dual legal marriage system where written statutory law and unwritten customary law exist side by side, most of these marriages may have been sanctioned under the customary law. It is this law under which, most early http://aps.journals.ac.za marriages take place as a child can be married when he/she reaches puberty. Moreover, $60 \%$ of Zambia's population according to the 2010 census (CSO, 20I2) resides in rural areas and since the majority gives primacy to customary law in most partsof the country, this may have also contributed to the high prevalence of child marriages.

In addition, the results show that women residing in the urban parts of North-Western and Western Provinces were less likely to get married before the age of 18. On the other hand, women residing in the rural parts of Copperbelt, Eastern and Southern Provinces were found to have higher odds of getting married below the age of 18 respectively. A qualitative study by Mann et al. (2015) made similar observations that women in rural parts of Zambia marry earlier than women in the urban areas and this was attributed to limited access to a range of programmes, information and services as well as 
limited opportunities for leisure \& recreation, skills development and employment.

The study also found that women who had their first birth before marriage had lower odds of being married early as compared to their counterparts who had their first birth after marriage. This is consistent with the results of the study undertaken by (Pazvakavambwa and Wanjau, 20I5). Having a child before marriage in Zambia was until very recently considered a social taboo, hence most men tend to shun marrying a woman who has had a child outside marriage in preference for one who has never had a child before. As such, most families tend to marry off their girl children while they are still young i.e. at an age before they start engaging in premarital sex as a preventive measure of pregnancy and also to avoid stigma that comes with a woman who has had a child before marriage.

The results also reveal that, women who had their first sex encounter before the age of 16 (underage) were twice as likely to get married below the age of I8 compared to those that had their first sexual encounter above the age of 16 . According to the ZDHS 2013-14, 58\% of women aged between 25 49 had their first sexual encounters by age 18 , meaning that sexual debuts among this age group of women occurs early hence their exposure to pregnancy starts at a relatively early age. A young girl's pregnancy outside of marriage in Zambia is seen as dereliction of parental duty. Therefore, to avert pregnancy before marriage many parents opt to marry off their girls at an early age. Many societies prize virginity before marriage especially the Bemba culture and this can manifest in a number of practices designed to protect a girl from unsanctioned sexual activity (Pazvakavambwa and Wanjau, 20I5). One such practice would be marrying them off at a very young age.

Household size was progressively found to be positively associated with child marriage. The results show that child marriages become more prevalent as the household size becomes larger. This finding is consistent with the finding by (Ali et. al., 2014) who found that an increase in family size burdened the economic status of the family hence lead to child marriage. A larger family size entails a high cost of raising children or little economic resources available to the household. As a result, families are willing to allocate those few resources to educating the boy child as opposed to the girl child, who is viewed as an economic burden and is perceived to have a low potential to earn an income in the future. Hence the girl will be married off early as a solution.

The study found that the prevalence of child marriages decreased as the level of education of the women increased. With women in tertiary education having the lowest odds of being married before the age of $18(90 \%)$, followed by those who had attained secondary education $(60 \%)$ then those with primary education (20\%) when compared to those without any formal education. This result is consistent with previous studies undertaken by (Sah et. al., 2014; Pandey, 2017; Population Council, 2017). Education of a woman entails delaying or postponing marriage and also gives the woman autonomy and power to take control of decisions that affect their lives such as marriage. The longer a girl stays in school, the less likely she is to be married before the age of 18 and have children during her teenage years. Therefore, as a woman climbs up the education ladder the risk of exposure to early marriage reduces.

Similarly, the education level of partners had an influence on child marriages. The prevalence of the women getting married before the age of 18 was lower as the partner's level of education increased. This result is consistent with that found by (Raj et. al, 2009; Pandey, 2017) which showed a higher prevalence of child marriage in women with less educated husbands than those with more educated husbands. The plausible explanation of this result is that, as a man becomes more educated, he is made aware of the laws surrounding marriage as well as acquires a better understanding of the adverse health consequences of female child marriage. He therefore, adheres to the statutory marriage laws and marries a woman legally ready for marriage.

\section{Factors influencing fertility (preferred number of children).}

With reference to the influence of child marriages on fertility in Zambia, the study found that the prevalence of adolescent birth among women who had married before age 18 was 1.08 times that among women who had married at 18 years old and above. This result is consistent with a number of studies indicating an association between child marriage and fertility (child bearing) (Mensch et. al., 1998; Williamson and Blum, 2013; Maswikwa et. al., 2015). The preference to have more children among women married before reaching the age of 18 as compared to their counterparts arises from society norms and practices. These norms and practices therefore impose pressure on them to have children soon after marriage. Often times, child brides are under great pressure to prove their fertility. The pressure often comes from their husbands and inlaws to reproduce in order to gain respect in society and preserve the family name.

Another variable that was found to be significant in explaining fertility preference was employment status of the women. The results reported higher fertility preference among women who were 
employed compared to those who were not employed. This finding is consistent with findings of (Salami and Oladodu, 2016; Wijesinghe, 2012) in which they found women's employment was positively related to the demand for another child. This result was attributed to the increase of the economic potential of women in employment which thus influenced their fertility intention. Women who are employed are financially capable to take care of a larger family by virtue of their employment, hence they desire to have more children. However, this finding was in contrast to a finding by (Nwakeze, 2010) who found that working can have the effect of depressing fertility through the mechanism of competition for a woman's personal resources; especially time.

The results revealed that the desire or preference to have many children declined as both the woman and her partner's education levels increased. This is consistent with the results by (Dreze and Murti, 2000). Education raises the opportunity cost of both women and men's time and generally opens up greater opportunities that often conflict with repeated child-bearing. This often reduces the desire to have many children especially among women. Moreover, as people attain higher levels of education, they are often faced with a decision of quality versus quantity of which they often choose the former due to economic resource constraints.

Finally, rural based women also prefer to have more children compared to their urban counterparts. This result is consistent with Adhikari (2010) who attributed it to low contraceptive intake among rural dwellers. In rural Zambia, the major economic activity is agriculture and children are seen as a very important resource in the household production function as they contribute to household income through labour. In addition, since many in these families do not have reasonable incomes that can act as a buffer, children are seen as a social safety net for old age security.

\section{Conclusion}

The scourge of childhood marriages unfortunately has many faces and working with a number of variables such as this study has done, helps us uncover the worst of the prevailing situation. The study sample distribution was such that, more than $50 \%$ of the women that were married before the age of 18 resided in rural areas. In terms of whether one belonged to a poor, rich or middle household the distribution was such that a larger part came from the rich households representing $42 \%$ of the distribution. The descriptive also showed that more than $50 \%$ of the women had their first sex before the age of 16 years. In terms of educational achievement, the majority of the women had attained basic primary school education whereas only $4.8 \%$ had a higher or tertiary education level. The sample distribution also indicated that almost three quarters of the women had access to some kind of media.

Much of the negative influence toward child marriages in this study was found to be among women who had their first sex before the age of 16 (underage). They had 100\% higher odds of getting married below the age of 18 compared to those above the age of 18. Larger households also showed higher odds of child marriages compared to small households. Undoubtedly, the higher the level of education of the women and their male counterparts, the lower the tendency towards early marriage. Thus, the results show that having tertiary education reduces the odds of early marriage by $90 \%$.

In terms of factors influencing fertility, the multiple Poisson regression results showed that the younger the age of marriage (below 18) the more the preferred number of children among women. Education status of both women and men had a positive influence on the number of preferred children, moreover, the rural based women had a higher incident rate for the preferred number of children compared to their urban counterparts.

\section{Policy implication}

The results of this study provide important insights for policy formulation on the issue of child marriages in Zambia. In order to address the high level of child marriages, this study encourages policies and legislation aimed at increasing the age at first marriage. Education is important for increasing the age at first marriage as such a policy should be directed towards improving access to education for girls and young women. Engaging the teenagers in formulating strategies to address the problem as well as sensitizing them about reproductive health and the importance of avoiding early sexual activity would go a long way in helping address the problem of child marriage and pregnancy. Considering that early marriage is a multifactorial problem, addressing it requires a multipronged strategy not only addressing factors identified in this study, but going beyond and addressing factors that drive gender inequalities. Moreover, addressing the problem of child marriages would help reduce fertility and problems related to fertility levels among other things.

\section{Acknowledgement}

The authors would like to thank DHS Programme for providing the dataset and Mr Kasongo Mumba for translating the abstract to French. 


\section{References}

Adhikari, R. 2010. Demographic, socio-economic, and cultural factors affecting fertility differentials in Nepal BMC Pregnancy and Childbirth 2010, 10:19.doi: 10.1 186/147I-2393-10-19

Ali AAA, Ibrahim IA, Abdelgbar SA, Elgessim ME (2014) Socio-Demographic Factors Affecting Child Marriage in Sudan. J Women's Health Care 3: 163. doi: $10.4172 / 2167-0420.1000163$

Amoo, E.O. 2017. Trends and determinants of female age at first marriage is Sub-Saharan Africa (1990-2014): What has changed? African Population Studies, Vol 3I No. I (Supp 2) 2017

Cristine A. Smith, C.A., Stone, R. P. and Kahando, S. (2012) A model of women's educational factors related to delaying girls' marriage, International Review of Education, Vol. 58, No. 4 (August 2012), pp. 533-555, Springer, http://www.jstor.org/stable/23255247, Accessed: 20-09-2017 I I:0 I UTC.

Central Statistical Office (CSO) [Zambia], Ministry of Health (MoH) [Zambia], and ICF International. Zambia Demographic and Health Survey 20I3-I4. Rockville, Maryland, USA: Central Statistical Office, Ministry of Health, and ICF International; 2014

Central Statistical Office (CSO) [Zambia]. 20I2. 2010 Census of Population and Housing National Analytical Report. Lusaka, Zambia: Central Statistical Office.

Central Statistical Office (CSO), Ministry of Health $(\mathrm{MOH})$, Tropical Diseases Research Centre (TDRC), University of Zambia, and Macro International Inc. 2009. Zambia Demographic and Health Survey 2007. Calverton, Maryland, USA: $\mathrm{CSO}$ and Macro International Inc.

Central Statistical Office [Zambia], Central Board of Health [Zambia], and ORC Macro. 2003. Zambia Demographic and Health Survey 200I-2002. Calverton, Maryland, USA: Central Statistical Office, Central Board of Health, and ORC Macro.

Central Statistical Office [Zambia] and Ministry of Health and Macro International Inc. 1997.Zambia Demographic and Health Survey, 1996. Calverton, Maryland: Central Statistical Office and Macro International Inc.

Dreze and Murti, 2000.Fertility, education and Development.Discussion Paper No. DEDPS 20, January 2000.

Gage AJ (20I3). Child marriage prevention in Amhara Region, Ethiopia: Association of communication exposure and social influence with parents/guardians' knowledge and attitudes. Social Science \& Medicine 97 (20I3) I24-I33. Available onhttp://dx.doi.org/10.1016/j.socscimed.2013.08. 017
Gillian Mann, Padraig Quigley and Rosal Fischer, 2015. Qualitative study of child marriage in six districts of Zambia, Hong Kong, Child Frontiers Ltd

Godha, D., Hotchkiss, D.R. and Gage, A.J. 2014. Association Between Child Marriage and Reproductive Health Outcomes and Service Utilization: A Multi-Country Study From South Asia. Journal of Adolescent Health 52 (2013) 552e558, http://dx.doi.org/I0.1016/j.jadohealth.2013.01.02

Green, C., Mukuria, A. and Rubin, D. 2009. Addressing Early Marriage in Uganda. Washington, DC: Futures Group, Health Policy Initiative, Task Order I.)

GRZ(n.d.) National Strategy on Ending Child Marriage in Zambia 2016 - 2021, Ministry of Gender, Government Complex, Lusaka.

Jennifer Parsons, Jeffrey Edmeades, AslihanKes, Suzanne Petroni, Maggie Sexton \& Quentin Wodon (2015) Economic Impacts of Child Marriage: A Review of the Literature, The Review of Faith \& International Affairs, 13:3, 12-22, DOI: 10.1080/I5570274.20I5.1075757

Kalamar, A.M., Lee-Rife, S. and Hindin, M.J. (2016) Interventions to Prevent Child Marriage Among Young People in Low- and Middle-Income Countries: A Systematic Review of the Published and Gray Literature, Journal of Adolescent Health $59 \quad$ (2016) SI6eS2I, http://dx.doi.org//0.1016/j.jadohealth.2016.06.015

Mann, Gillian, Padraig Quigley, and Rosal Fischer. 2015. "Qualitative Study on Child Marriage in Six Districts of Zambia." Sheung Wan, Hong Kong: Child Frontiers for UNICEF.

Male, Chata; Wodon, Quentin T.. 2016. Basic profile of early childbirth in Zambia (English). Health, nutrition, and population (HNP) knowledge brief : child marriage series. Washington, D.C. : World Bank Group. http://documents.worldbank.org/curated/en/4374 4|467996655 167/Basic-profile-of-early-childbirthin-Zambia

Mangeli $M$. et al. Factors that encourage early marriage and motherhood from the perspective of Iranian adolescent mothers: a qualitative study .World Family Medicine. 20I7; I5(8):67-74. DOI 10.5742/MEWFM.2017.93058)

Maswikwa,B., Richter,L. Kaufman, J. and Nandi, N.(20I5) Minimum Marriage Age Laws and the Prevalence Of Child Marriage and Adolescent Birth: Evidence from Sub-Saharan Africa, International Perspectives on Sexual and Reproductive Health, 20I5, 4I(2):58-68, doi: 10.1363/41058I5 Volume 4I, Number 2, June 2015. 
Mensch B, Bruce J and Greene M, The Uncharted Passage: Girls' Adolescence in the Developing World, New York: Population Council, 1998.

Nour, N.M. (2006) Health Consequences of Child Marriage in Africa, Emerging Infectious Diseases.www.cdc.gov/eid - Vol. 12, No. II, November 2006.

Nour, N. M. (2009). Child marriage: a silent health and human rights issue. Reviews in Obstetrics \& Gynecology, 2(I), 5I-56.

Nsemukila, B. 2015."Assessment of the Regulatory Frame-work for Maternal, Newborn, Child Health and Nutrition (MNCH\&N) Services in Zambia."Millennium Development Goal Initiatives and Government of the Republic of Zambia.

Nwakeze N.M, 2010. Gender and Labour Force Participation in Nigeria: Issues and Prospects. International Journal of Research in Arts and Social Sciences, Vol 2 pp 477 - 492, 2010.

Pandey Shanta, Persistent nature of child Marriage among women even when it is illegal: The case of Nepal. Children and Youth Services Review 73 (2017) 242-247. Available from http://dx.doi.org//0.1016/j.childyouth.2016.12.02 I

Panos Institute Southern Africa (PSAf), 20I4. Media Brief on Ending Child Marriages in Zambia, Media Brief, Zambia.

Population Council, UNFPA, and Government of the Republic of Zambia. 2017. "Child Marriage in Zambia." Lusaka, Zambia.

Plan International, 2016. Ending Child Marriage in Zambia: Gaps and Opportunities in Legal and Regulatory Frameworks: The 18+ Programme on Ending Child Marriage; Policy Brief, Zambia.

Pazvakavambwa, B and Wanjau, C. 20I5. Preliminary Research Into The Extent, Factors And Effects Of Child Marriage Research In Zambia, Zimbabwe And Malawi. Final Report, VSO RHAISA, Pretoria.

Population Council, UNFPA, and Government of the Republic of Zambia. 2017. "Child Marriage in Zambia." Lusaka, Zambia.

Population Council, UNFPA, and Government of the Republic of Zambia. 2017. "Child Marriage in Zambia." Lusaka, Zambia.

Raj, A. (20/0). When the mother is a child: The impact of child marriage on the health and human rights of girls. Archives of Disease in Childhood, 95(II), 93I-935.

Raj A, Saggurti N, Balaiah D, et al. Prevalence of child marriage and its effect on fertility and fertility control outcomes of young women in India: a cross sectional, observational study. The lancet 2009;373: I 883-9.

http://dx.doi.org/I0.I0I6/S0|40-6736(09)60246-4
Sah RB, Gaurav K, Baral DD, Subedi L, Jha N, Pokharel PK. Factors affecting Early Age Marriage in Dhankuta Municipality, Nepal. Nepal Journal of Medical Sciences 20I4;3(I):26-30.

Salami I.C. and Oladosu M. Factors Influencing Women's Employment Status and Fertility Preferences among Married Women in SouthSouth Region of Nigeria. 3rd International Conference on African Development Issues (CUICADI 2016)

SiminMontazeri et al. 2016. Determinants of Early Marriage from Married Girls' Perspectives in Iranian Setting: A Qualitative Study. Hindawi Publishing Corporation Journal of Environmental and Public Health Volume 2016, Article ID 8615929, 8 pages http://dx.doi.org/I0.I I55/2016/86/5929

United Nations Children's Fund. (201 I). The state of the world's children 201 I. New York: United Nations Children's Fund.

United Nations Children's Fund, Ending Child Marriage: Progress and prospects, UNICEF, New York, 2014.

UNICEF, 2018a.Child Marriage. [https://data.unicef.org/topic/child-

protection/child-marriage/]. Accessed: $\quad 17$ September, 2018

UNICEF, 20I8b.I Child marriage - Latest trends and future prospects. Data and Analytics Section, United Nations, New York, USA

Walker, J.A. 2016. Why ending child marriage needs to be an education goal'

Williamson $\mathrm{N}$ and Blum R, Motherhood in Childhood: Facing the Challenge of Adolescent Pregnancy, New York: United Nations Population Fund, 2013.

Wijesinghe M.D.J.W. Women's Labour Force and Fertility Preference, Sri-Lanka Economic Research Conference 20I2. Pp I73-I78

Wodon, Q., C. Male, A. Nayihouba, A. Onagoruwa, A. Savadogo, A. Yedan, J. Edmeades, A. Kes, N. John, L. Murithi, M. Steinhaus and S. Petroni (2017). Economic Impacts of Child Marriage: Global Synthesis Report, Washington, DC: The World Bank and International Center for Research on Women.

Workineh,S., Kibretb, G.D. and Degu, G. (20/6) Determinants of Early Marriage among Female Children in Sinan District, Northwest Ethiopia. Health Science Journal, Vol. 9 No. 6: I, ISSN I79I809X

Yvette Efevbera, Jacqueline Bhabha, J.D., Paul E. Farmer, Günther Fink, (2017) Girl child marriage as a risk factor for early childhood development and stunting, Social Science \& Medicine 185 (20I7) 91 elol, 
African Population Studies Vol. 32, No.2, Oct./Nov. 2018

http://dx.doi.org/10.1016/j.socscimed.2017.05.02 Zambia Situation Analysis of Children and Women 70277-9536/C 2017 Elsevier Ltd. All rights 2008. United Nations Children's Fund (UNICEF), reserved. 2009. 